\title{
Improvement of Drug Delivery by Electrospun Nanofibers
}

\author{
Nahid Sarlak* and Maryam Mousakhani \\ Department of Chemistry, Lorestan University, Iran \\ *Corresponding author: Nahid Sarlak, Department of Chemistry, Lorestan University, Iran
}

\begin{tabular}{|c|c|}
\hline ARTICLE INFO & ABSTRACT \\
\hline $\begin{array}{l}\text { Received: 㹃 November 14, } 2019 \\
\text { Published: 慧 November 20, } 2019\end{array}$ & $\begin{array}{l}\text { Electrospinning is easy technique that offers great flexibility in high loading } \\
\text { capacity, selecting materials and high encapsulation efficiency, that makes it proper for } \\
\text { medical study such as wound healing, tissue engineering and regenerative medicine and }\end{array}$ \\
\hline $\begin{array}{l}\text { Citation: Nahid Sarlak, Maryam } \\
\text { Mousakhani. Improvement of Drug } \\
\text { Delivery by Electrospun Nanofibers. } \\
\text { Biomed J Sci \& Tech Res 23(1)-2019. }\end{array}$ & $\begin{array}{l}\text { materials by blending into a solution of the encapsulating polymer or coaxial } \\
\text { electrospinning to produce core-shell structures. The release profile of a drug into the } \\
\text { body can be designed and controlled by careful selection of the fiber composition and } \\
\text { control of its size, structure and morphology. This study reviews several aspects of } \\
\text { electrospinning in the use of electrospun nanofibers in drug delivery. }\end{array}$ \\
\hline
\end{tabular}

BJSTR. MS.ID.003852.

Keyword: Electrospinning; Nanofiber; Drug delivery; Biomedical science

\section{Introduction}

In the field of tissue engineering and regenerative medicine, electrospinning devices for medical applications are used to make materials and structures that closely mimic the native more cellular matrix within our tissues in order to provide optimum conditions for the repair of damaged tissues. Electrospinning devices are also used in the development of wound care products. The high degree of porosity, small pore sizes and large surface area of electrospun mats make them ideal for use in wound dressings, where they provide effective protection against bacterial infection of the wound surface whilst allowing the exchange of wound fluids and gasses through the dressing. Electrospinning devices can be used in the development of drug delivery systems. Active pharmaceutical ingredients can be incorporated into electrospun materials by either blending into a solution of the encapsulating polymer, or by coaxial electrospinning to create core-shell structures. The release profile of a drug into the body can be designed and controlled by careful selection of the fiber composition and control of its size, morphology and structure. The encapsulation of bioactives and/or pharmaceutical ingredients by electrospinning can provide protection against their degradation or interaction with their environment [1].

\section{Electrospun Nanofibers in Drug Delivery}

\section{Vitamins}

Electrospun fibers of vitamins, antioxidant and antiinflammatory drugs are mostly given by transdermal route $[2,3]$. The transdermal drug delivery system delivers the drugs locally or systemically via the skin. This is suitable for drugs that cannot be taken by the oral route [4]. Taepaiboon et al. have loaded vitamin E and vitamin A in cellulose acetate polymer-based electrospun fibers [5]. The results confirmed that the electrospun fiber mats had a regular and constant increase in the cumulative vitamin release assayed using a total immersion technique over the test period of $24 \mathrm{~h}$ for vitamin $\mathrm{E}-$ and $6 \mathrm{~h}$ for vitamin A-loaded fiber.

\section{Antibiotics}

In recent years, antibiotics and antibacterial agents have been the most common drug molecules that are encapsulated, using different polymers and their combinations as carriers. Different polymers are primarily used in the polymeric electrospun fibers for biodegradability, and other natural and synesthetic hydrophilic 
or hydrophobic polymers are used to control the release pattern of the drug. Kenaway et al. used tetracycline hydrochloride with poly (ethylene-co-vinyl acetate) (PEVA), PLA and their 50:50 blend to deliver the drug for treating periodontal disease [6]. They reported over five days of release with PEVA and the blend, suggesting their applicability in controlled-release technology.

\section{Anticancer Agents}

Anticancer agents have been incorporated into electrospun fibers with polymers such as PLA, PLGA and PLLA for postoperative chemotherapy. A water in oil emulsion, with water soluble drugs in aqueous phase and polymeric solutions of PEG-PLA in chloroform as oily phase, was prepared and electrospun to obtain fibers [7]. In a study, hydrophobic paclitaxel and hydrophilic doxorubicin were simultaneously loaded in the emulsion-based electrospinning process for multi-drug delivery [8]. The cytotoxicity study of rat Glioma C6 cells showed higher inhibition and apoptosis in combination therapy compared to the single-drug system. In another report, an in vitro cytotoxicity study of the same cells showed a sustained release of platinum-based cisplatin for more than 75 days without burst release and four times better cytotoxicity

\section{Nanoparticle Filled Nanofibers}

Electrospun nanofibers containing nanoparticles has been usually studied for different applications. In drug delivery, these novel impregnated nanofibers are being explored in the areas of wound care, dental engineering, regenerative medicine and for cancer treatment. A research conducted by Lee et al. studied the efficacy of chitosan (CTS) nanofibers containing silver nanoparticles for topical wound care. The nanoparticle solution obtained was then poured into sodium hydroxide resulting in the formation of CTS/AgNPs composite, which was further subjected to electrospinning to form nanofibers. The prepared fibers showed excellent antibacterial activity against $P$. aeruginosa and methicillinresistant S. aureus when compared to the pure CTS nanofibers [10].

\section{Conclusion}

By suitable selection of polymers, it is now possible to deliver various anticancer drugs and antibacterial agents in a required

\section{ISSN: 2574-1241}

DOI: 10.26717/BJSTR.2019.23.003853

Nahid Sarlak. Biomed J Sci \& Tech Res

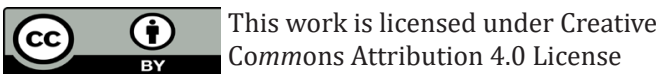

Submission Link: https://biomedres.us/submit-manuscript.php manner using electrospun nanofibers. In order to make further progress, it is necessary to identify means that allow largescale fabrication of nanofibers with desired mechanical and morphological properties in a reproducible manner. Further progress in the field of electrospun nanofibers will require continued assessment in vivo.

\section{References}

1. Huang ZM, Zhang YZ, Kotaki M, Ramakrishna S (2018) A review on polymer nanofibers by electrospinning and their applications in nanocomposites. Compos Sci Technol 63: 2223-2253.

2. Suwantong O, Ruktanonchai U, Supaphol P (2008) Electrospun cellulose acetate fiber mats containing asiaticoside or Centella asiatica crude extract and the release characteristics of asiaticoside. Polymer 49: 42394247.

3. Taepaiboon P, Rungsardthong U, Supaphol P (2006) Drug-loaded electrospun mats of poly (vinyl alcohol) fibres and their release characteristics of four model drugs. Nanotechnology 17: 2317.

4. Im JS, Lee SK, Bai BC, Lee YS (2012) Prediction and characterization of drug release in a multi-drug release system. J Ind Eng Chem 18: 325-330.

5. Taepaiboon P, Rungsardthong U, Supaphol P (2007) Vitamin-loaded electrospun cellulose acetate nanofiber mats as transdermal and dermal therapeutic agents of vitamin A acid and vitamin E. Eur J Pharm Biopharm 67(2): 387-397.

6. Kenawy ER, Bowlin GL, Mansfield K, Layman J, Simpson DG, et al. (2002) Release of tetracycline hydrochloride from electrospun poly(ethyleneco-vinylacetate), poly (lactic acid), and a blend. J Control. Release 81: 57-64.

7. Xu X, Chen X, Ma P, Wang X, Jing X (2008) The release behavior of doxorubicin hydrochloride from medicated fibers prepared by emulsionelectrospinning. Eur J Pharm Biopharm 70(1): 165-170.

8. Xu X, Chen X, Wang Z, Jing X (2009) Ultrafine PEG-PLA fibers loaded with both paclitaxel and doxorubicin hydrochloride and them in vitro cytotoxicity. Eur J Pharm Biopharm 72(1): 18-25.

9. Xie J, Tan RS, Wang CH (2008) Biodegradable microparticles and fiber fabrics for sustained delivery of cisplatin to treat C6 glioma in vitro. J Biomed Mater Res Part A 85(4): 897-908.

10. Lee SJ, Heo DN, Moon JH, Ko WK, Lee JB, et al. (2014) Electrospun chitosan nanofibers with controlled levels of silver nanoparticles. Preparation, characterization and antibacterial activity. Carbohydr. Polym 111: 530-537. 